\title{
The influence of part of speech on paired-associate learning '
}

\author{
S. I. SHAPIRo aho daVId S. PALERMo \\ PENNSYLVANIA STATE UNIVERSITY
}

Two experiments assessed the influence of part of speech of the stimulus and response on paired-associate learning. Experiment 1 indicated that noun pairs were learned faster than adjective, verb, or adverb pairs, and adjective pairs were leamed faster than adverb pairs. Experiment 2 indicated that noun pairs were learned faster than adverb, pronoun, or preposition pairs, and pronoun pairs were leamed faster than preposition pairs.

Recent studies indicate that words of different parts of speech may vary in their difficulty for certain verbal learning tasks. Differences in performance as a function of part of speech have been reported in serial learning (Simpson, 1965), free recall (Rosenberg, 1965), and paired-associate learning (Epstein, Rock, \& Zuckerman, 1960; Glanzer, 1962).

Glanzer (1962), employing nonsense syllables as stimuli or responses, and Epstein et al (1960), using word pairs, found that performance on content words was better than on function words. 2 The present investigation, like Epstein et al, also employed word pairs to study the influence of part of speech on paired-associate learning. However, in the present study, a greater variety of parts of speech was examined, and interitem associations and word frequencies were more rigorously controlled.

Experiment 1 employed the four content words classes of nouns, adjectives, verbs, and adverbs. Experiment 2 employed the two content word classes of nouns and adverbs, and the two function word classes of pronouns and prepositions. Interjections and conjunctions were not studied because normative association data were lacking for interjections, while the conjunctions available were highly interassociated.

\section{Experiment 1}

\section{Lisis}

Six nouns, adjectives, verbs, and adverbs were selected from normative free association data for college males so as to minimize associative connections among the words. Nineteen of the words were selected from Palermo \& Jenkins' (1964a) norms and the remaining five from unpublished data of Deese. 3 The words, followed by their Thorndike-Lorge (1944) frequencies of occurrence, were: (1) Nouns-city (AA), justice (A), ocean (AA), fingers (A), numbers (AA), bread (A); (2) Adjectives-cold (AA), afraid (AA), rough (A), short (AA), heavy (AA), loud (A); (3) Verbs -live (AA), stand (AA), tell (AA), buying (AA), become (AA), eating (AA); (4) Adverbs-also (AA), away (AA), seldom (A), down (AA), greatly (A), quickly (AA). In cases where words could be classified as more than one part of speech, the first and presumably most frequent classification in the Thorndike-Barnhart Comprehensive Desk Dictionary (Barnhart, 1951) were ar- bitrarily employed. Of the 552 possible interitem associations there were nine, with a mean associative strength of $0.5 \%$. There were no forward or reverse associations in the normative data between any words subsequently paired in the lists.

Three forms of a list of 12 paired associates each were constructed from the 24 words, each pair consisting of words from the same part of speech. Thus, each list contained three pairs from each of the four parts of speech. The same 12 words always served as stimuli, but the responses within a part of speech were rotated to provide the three list forms. The 12 stimulus words were originally selected from the norms so that their primary response strengths were roughly equated across parts of speech inasmuch as paired-associate learning of stimuli and unassociated responses appears to be influenced by the primary response strength to the stimuli (Palermo \& Jenkins, 1964b). Four orders of each list were prepared in which the pairs were randomized with the restrictions that a given pair never occupied the initial position in the orders of a list twice and never appeared twice in succession. In addition, within each order, a pair from each part of speech was presented before another pair from the same class was presented. Procedure and Subjects

The lists were presented by means of a memory drum at a 2:2:4-sec rate. The Ss were instructed to pronounce both stimuli and responses on the initial trial and thereafter only to anticipate the response members of the pairs. The learning criterion was two successive errorless trials. Any $S$ failing to reach criterion within 40 trials was excluded.

The Ss were 30 male students fulfilling a course requirement in introductory psychology classes at the Pennsylvania State University. Each of the three lists was learned by 10 different Ss. An additional $15 \mathrm{Ss}$ were eliminated after the initial trial for having pronounced the word live as an adjective, whereas this word was employed as a verb in the list. One more $S$ was excluded for failing to reach the learning criterion.

\section{Experiment 2}

Lists

Six nouns, adverbs, prepositions, and pronouns were selected from normative free association data for college males so as to minimize any associative connections among the words. Twenty of the words were selected from the Palermo-Jenkins norms and the remaining four from the Deese norms. The words, followed by their Thorndike-Lorge frequencies of occurrence were: (1) Nouns-music (AA), fruit (AA), north (AA), bed (AA), hand (AA), boy (AA); (2) Adverbs-however (AA), slowly $(A)$, always (AA), down (AA), hardly (A), very (AA); (3) 
Prepositions -for (AA), over (AA), before (AA), on (AA), by (AA), from (AA); (4) Pronouns-we (AA), yourself (AA), his (AA), this (AA), it (AA), who (AA). Part of speech classification was again based upon the Thorndike-Barnhart dictionary. Of the 552 possible interitem associations there were 60 , with a mean associative strength of $0.8 \%$. In the actual lists constructed, 16 of the interitem associations turned out to be intrapair associations, 9 of which were reverse associations; the mean forward strength of the intrapair associations was $0.9 \%$ and the mean reverse strength was $0.7 \%$.

Three forms of a list of 12 paired associates each were constructed following the procedure described in Experiment 1. The words employed for the stimulus members of the pairs were again originally selected to roughly equate the associative strengths of their primary responses across parts of speech.

\section{Procedure and Subjects}

The procedure for Experiment 2 was the same as for Experiment 1 except the intertrial interval was $8 \mathrm{sec}$.

The Ss were 30 male students obtained from the same pool as in Experiment 1, but no $S$ served in the earlier experiment. Each of the three lists waslearned by 10 different Ss. Two additional Ss were excluded from the experiment, one because of apparatus failure and the other for fallure to reach the learning criterion.

\section{Results and Discussion}

In Experiment 1, the mean number of errors was $10.53(\mathrm{SD}=6.65)$ for nouns, $19.17(\mathrm{SD}=10.59)$ for adjectives, $22.63(\mathrm{SD}=11.59)$ for verbs, and 25.47 (SD =11.68) for adverbs. A Treatment by Subjects analysis of variance applied to these data indicated a significant treatments effect $(F=21.38, d f=3 / 87, p<.01)$. Significantly fewer errors occurred for nouns than for adjectives, verbs, or adverbs $(t=4.98,6.49,6.30, d f=29$, $\mathrm{p}<.001)$. The difference between adjectives and adverbs was significant $(t=3.40, d f=29, p<.01)$, but the difference between adjectives and verbs and between verbs and adverbs did not reach an acceptable level of statistical significance $(t=1.78,1.38, d f=29)$.

In Experiment 2, the mean number of errors was 7.03 $(\mathrm{SD}=5.97)$ for nouns, $18.36(\mathrm{SD}=10.68)$ for pronouns, 21.80 ( $\mathrm{SD}=11.61$ ) for adverbs, and $25.23(\mathrm{SD}=14.21$ ) for prepositions. A Treatments by Subjects analysis of variance indicated a significant treatments effect $(F=29.60$, $d f=3 / 87, p<.01)$. Signiflcantly fewer errors occurred for nouns than for adverbs, pronouns, or prepositions $(t=8.37,7.21,8.15, d f=29, p<.001)$. The difference between pronouns and prepositions was significant $(t=2.70$, $\mathrm{df}=29, \mathrm{p}<.02$ ), but the difference between adverbs and pronouns and between adverbs and prepositions did not reach an acceptable level of statistical significance $(t=$ $1.74,1.64, \mathrm{df}=29$ ). For both experiments, the mean numbers of errors reported above generally reflect performance on a trial by trial basis as well.

The results of Experiments 1 and 2 indicate that ease of paired-associate learning is influenced by the part of speech of the word pairs employed. The superior performance on nouns, as contrasted with other parts of speech, also appears in serial learning (Simp446 son, 1965), free recall (Rosenberg, 1965), and previous studies of paired-associate learning (Glanzer, 1962; Epstein et al, 1960). The influence of other parts of speech in these studies has not been as consistent as that of nouns. The rank order of learning difficulty for the parts of speech of the present study reasonably approximates the results obtained by Glanzer (1962, Experiment 1) who employed a similar range of parts of speech but not word-word pairs.

It is of some interest to note that in meaningfulness data made available subsequent to the present study, 4 the mean $\underline{m}$ value (as defined by Noble, 1952) for all content words $(\mathrm{N}=168)$ of the Palermo-Jenkins norms was 11.89 (highest for nouns) and 11.11 for function words $(\mathrm{N}=32)$. Thus, the finding that content words are learned faster than function words (Glanzer, 1962; Epstein et al, 1960) may (partially) reflect a difference in the $\underline{m}$ values for the two classes of words. There was also some indication that the $m$ values for the words in Experiments 1 and 2 selected from the Palermo-Jenkins norms were higher for the more easily learned parts of speech. It would therefore be desirable to experimentally determine to what extent the influence of parts of speech on paired-associate learning is independent of differences in meaningfulness.

\section{References}

Bamhart, C. I. Thorndike-Barnhart comprehensive desk dictionary. Garden City, New Yorik: Doubleday, 1951.

Epstein, W., Rock, I., \& Zuckerman, C. B. Meaning and familiarity in associative learning. Psychol. Monogr., 1960, 74, No. 4.

Glanzer, M. Grammatical category: A rote learning and word association analysis. J, verbal Learn. verbal Behav., 1962, 1, 31-41.

Noble, C. E. An analysis of meaning. Psychol. Rev., 1952, 59, 421-430.

Pal ermo, D. S., \& Jenkins, J. J. Word association norms: Grade school through college. Minneapolis: University of Minnesota Press, 1964a.

Palermo, D. S., \& Jenkins, J. J. Paired-associate learning as a function of the strength of links in the associative chain. $J$. verbal Learn. verbal Behav., 1964b, 3, 406-412.

Rosenberg, $S$. The influence of grammatical and associative habits on learning. In S. Rosenberg (Ed.), Directions in psycholinguistics. New York: Macmillan, 1965.

Simpson, W. E. Effects of approximation to sentence word-order and grammatical class upon the serial learning of word lists. $J$. verbal Learn. verbal Behav., 1965, 4, 510-514.

Thomdike, E. L., \& Lorge, I. The teacher's word book of 30,000 words. New York: Teacher's College, Columbia University, 1944.

\section{Notes}

1. This research was supported by National Science Foundation Grant GB- 2568 and by Public Health Service research career program award HD-28, 120 from the National Institute of Child Health and Human Development to the second author. Preparation of this manuscript was completed during the first author's tenure as a Postdoctoral Fellow at the Institute of Human Learning, University of California, Berkeley. The Institute is supported by grants from the National science Foundation and the National Institutes of Health.

2. See Glanzer (1962) for a discussion of the distinction between content and function words.

3. We are grateful to Professor James Deese for providing these norms based upon the responses of 50 Johns Hopkins male undergraduates.

4. The Ss were 50 male and 50 female students at the Pennsylvania State University.

Psychon. Sci., 1967, Vol. 8 (10) 